\title{
ICONICITY AND CONVENTION IN THE MANUAL MODALITY: PANTOMIME IN LANGUAGE ORIGINS
}

\author{
ERICA A. CARTMILL \\ cartmill@anthro.ucla.edu \\ Department of Anthropology, University of California, Los Angeles, USA
}

Iconicity features prominently in manual communication systems, from cospeech gesture to fully-structured sign languages. Despite early reports to the contrary (Orlansky \& Bonvillian, 1984), there is growing evidence that iconicity aides in the early acquisition of signed languages (Thompson et al., 2012), though older children benefit more (Magid \& Pyers, 2017) and there may be different effects in second language learning (Ortega, 2017). Of course, iconicity is not limited to the gestural realm. Recent studies show that spoken languages contain many iconic elements, particularly in child speech (Monaghan et al., 2014; Perry et al., 2017). In sum: iconicity is prevalent in language, and may even be a driver of linguistic form (Dingemanse et al., 2015).

Iconicity is important to discussions of the evolution of language because iconic communication could, in principle, be understood without a shared linguistic system (i.e., without language). "Gesture first" theories of language origins emphasize the importance of iconicity as a bridge to language, arguing that iconic gesture could have provided an advantage to human ancestors before the emergence of language (e.g., Zlatev, 2008; Arbib, 2015). These authors propose that iconic gesture in the form of pantomime formed a transitional stage in the evolution of symbolic communication, between the ability to imitate actions and the emergence of communicative conventions. This is a compelling story, but I argue that iconicity (especially pantomime) did not play a substantial role in language origins until well after the emergence of conventional systems.

Despite the prevalence of iconic words and signs in modern languages, iconicity of the sort required by these theories is not a trivial matterunderstanding and producing iconic gestures requires complex mental representation and sophisticated analogic reasoning. This may put it beyond reach of very young children and non-human primates, which raises questions 
about whether iconic gesture and pantomime could be stepping-stones to symbolic, codified language.

Recent work on iconicity has focused on identifying iconic features in conventional languages (like spoken English or ASL). However, it might reveal more about the underlying cognitive demands to study non-conventionalized systems (e.g., co-speech gesture or homesign). These systems do not primarily rely on shared conventions and may better reflect children's own understanding of iconicity. Hearing children do not begin using iconic gestures until relatively late in development, after they have mastered both conventional and indexical gestures. Use of iconic gesture undergoes a rapid period of growth around 2.5 years of age (Özçalişkan \& Goldin-Meadow, 2011). However, little is known about the cause of this growth, particularly whether it is driven by cognitive or communicative constraints. If understanding iconicity is indeed a complex task, then we might expect it to be more closely linked to cognitive development.

Using data from a recent study comparing the development of manual iconicity in co-speech gesture and homesign over the first 5 years of life (Cartmill et al., 2017), I explore the relevance of iconic gesture development for theories proposing pantomime as an evolutionary stepping-stone to conventional language. Homesign is vastly different from co-speech gesture, and has many structural properties of language (unlike gesture). Nevertheless, homesigners and hearing children show many similarities in the ways they begin to use their hands to reference the world iconically without conventional models of appropriate sign forms, particularly in the way the hand maps to aspects of objects or events (e.g., is the gesturing hand an hand or an object). These similarities suggest that the ability to use iconicity in the manual modality may develop in similar ways in both gesturing and homesigning children, supporting the theory that the growth spurt in iconic gesture has more to do with cognitive development than with the particular features of the linguistic system.

This similarity has direct implications for gesture first theories. While iconicity may help children learn words in conventional (spoken or signed) languages, the linguistic framework may provide crucial support for correctly interpreting the iconic features of unknown words. Manual iconicity without the support of conventional manual structures may not confer the same advantages. The presence of sound-symbolic words and iconic features of signed languages may thus tell us little about the likelihood of a pantomimic protolanguage. 


\section{References}

Arbib, M. A. (2012). How the brain got language: The mirror system hypothesis (Vol. 16). OUP USA.

Cartmill, E. A., Rissman, L., Novack, M. A., \& Goldin-Meadow, S. (2017). The development of iconicity in children's co-speech gesture and homesign. Language, Interaction and Acquisition, 8(1), 42-68.

Dingemanse, M., Blasi, D. E., Lupyan, G., Christiansen, M. H., \& Monaghan, P. (2015). Arbitrariness, iconicity, and systematicity in language. Trends in Cognitive Sciences, 19(10), 603-615.

Magid, R. W., \& Pyers, J. E. (2017). "I use it when I see it": The role of development and experience in Deaf and hearing children's understanding of iconic gesture. Cognition, 162, 73-86.

Monaghan, P., Shillcock, R. C., Christiansen, M. H., \& Kirby, S. (2014). How arbitrary is language?. Phil. Trans. R. Soc. B, 369(1651), 20130299.

Orlansky, M. D., \& Bonvillian, J. D. (1984). The role of iconicity in early sign language acquisition. The Journal of Speech and Hearing Disorders, 49(3), 287-292.

Ortega, G. (2017). Iconicity and Sign Lexical Acquisition: A Review. Frontiers in Psychology, 8.

Özçalişkan, Ş., \& Goldin-Meadow, S. (2011). Is there an iconic gesture spurt at 26 months? Integrating gestures: The interdisciplinary nature of gesture. Amsterdam, NL: John Benjamins.

Perry, L. K., Perlman, M., Winter, B., Massaro, D. W., \& Lupyan, G. (2017). Iconicity in the speech of children and adults. Developmental Science.

Thompson, R. L., Vinson, D. P., Woll, B., \& Vigliocco, G. (2012). The road to language learning is iconic: Evidence from British Sign Language. Psychological science, 23(12), 1443-1448.

Zlatev, J. (2008). The co-evolution of intersubjectivity and bodily mimesis. The shared mind: Perspectives on intersubjectivity, 215-244. 